Research Square
Preprints are preliminary reports that have not undergone peer review.

They should not be considered conclusive, used to inform clinical practice, or referenced by the media as validated information.

\title{
Screen-printing of microfibrillated cellulose for an improved moisture management, strength and abrasion resistant properties of flame-resistant fabrics
}

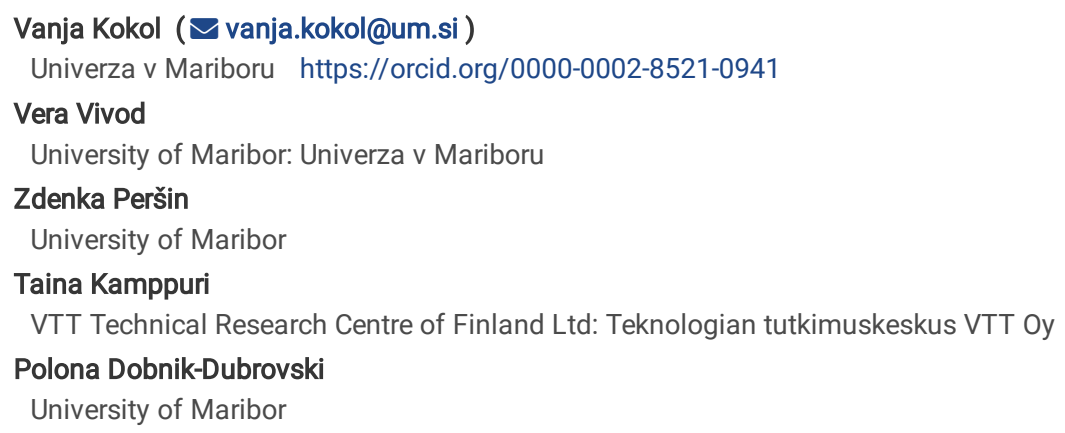




\section{Abstract}

Low moisture absorbency of hydrophobically coated flame-resistant (FR) fabrics do not correlate well with the thermophysiological comfort. In this frame, we were the first to study the effect of screen-printed microfibrillated cellulose (MFC) on fabric's breathability and moisture build-up and transfer as user-friendly and wear-related comfortable coating. The amount of MFC applied and its patterning was varied using different printing parameters, and the density and thickness of FR fabric, and studied by add-on measurement and microscopic imaging. The effect of MFC coating and its durability (attachment) after a postprinting of hydrophobic polyacrylate on the same (layer-by-layer) or other side of the fabrics was considered, thus to maintain one side of the fabric (facing towards the wearer) hydrophilic while keeping the other side (facing outward) hydrophobic.

The results showed that MFC provides uniform and repeatable printing, which gave homogeneous patterning with good layering on the fabrics, although, resulting in the MFC concentration, squeegee' pressure, and fabric' structure dependent add-on, its imprinting and co-crosslinking within the polyacrylate. This slightly reduced the fabric air-permeability, but increased it surfaces wetting, moisture uptake kinetic and capacity (hydroscopicity), without affecting the water vapour transfer. Besides, the polyacrylate could fix the MFC pre-printed on the other side of the fabric, thus maintaining its hydrophilicity, being more pronounced in the case of less open and thicker fabric, while improving its tensile /tear strengths and abrasion resistance, without deterioration of the fabric's flammability.

\section{Introduction}

A lot of innovations in the development of heat-resistant and flame-protective textiles, used for firefighters, military and space personnel, and other foundry and industrial workers, have been carried out over the last decade, and they will continue in the near future as a fast-growing segment to meet the requirements of new high-end functions for cutting-edge applications, such as intelligent and wearable self-powering technologies (Levett et al, 2020; Stoppa and Chiolerio, 2014; Zeng et al., 2014). In the process of accomplishing both of the above protection requirements, such a garment should, namely, provide, good thermophysiological comfort during wearing, when the body temperature rises and the wearer becomes wet by sweating (Zhu et al., 2017a and b). While the disadvantage of using the majority of flame-resistant (FR) synthetic fibres used in this area of applications (as aramids and acrylates) is associated with low moisture absorbency, which does not correlate well with the comfort (Havenetih et al., 2003), the blends with cotton or Lenzing FRß viscose (containing FR phosphorous/sulphur additives) fibres possessing high sorption properties are used in the fabric construction to achieve both functionality and comfort (Grgac et al., 2017). However, such functional fabrics should also be breathable and waterproof, to prevent liquid moisture from outside passing through, but allow moisture vapour to transfer from inside, thus providing thermal comfort properties. At high activity, heat is, namely, released from the body via liquid moisture (sweat), which should not spread on the inner surface of the garment as it can cause discomfort, but rarely absorbed by the fabric, and transferred to the outer face as fast as possible. Numerous studies have been performed using chemical and physical treatments, which can enhance some of these properties, but may impact adversely on other things, such as the fabric's rigidity and air permeability. Bifacial hybrid fabrics have thus been introduced recently, showing greater and faster moisture transfer properties (Zhu et. al., 2017a) with better heat transfer (Zhu et. al., 2017b), as well as an improved strength and abrasion resistance (Zhu et. al., 2018).

Nanotechnology plays a very important role in the developing of novel highly-functional and protective textiles by providing flexibility, stretchability, permeability, lightweight and durability to the fabrics, with significantly increased levels of functionality/protection and improved comfort (Krifa and Prichard, 2020). This trend also goes in the direction of environment and user friendly products, which, however, are still challenging and difficult to achieve.

Nano- and Microfibrillated Cellulose (NMC), a biodegradable, low cost, and lightweight nanomaterial (Jonoobi et al., 2015; Klemm et al., 2018; Zeng et al., 2020) produced from renewable resources, is also a promising nanomaterial for this segment of applications. The usage of NMC has been expanded from production of packaging, paper and board, up to flexible films, acting as thermal insulators, or new functional materials applied in electronics (Abitbol et al., 2016), energy storage (Wang et al, 2020), electromagnetic interference shielding (Zeng et al., 2020), solar cells (Du, Zhang, Liu, \& Deng 2017), (photo)catalysis (Kaushik \& Moores, 2016) etc. These possibilities of NMC are related to its significant physical and chemical properties, above all, high crystallinity, low density, extraordinary mechanical properties and nanoscale dimension, that give high surface area (Klemm et al., 2018) with huge amounts of hydroxyl (-OH) groups available for hydrogen bonding. In addition, the NMC has also been used as a strengthening additive in cement, plastic and paper (Boufi et al., 2016; Klemm et al., 2018). Moreover, good shear-thinning behaviour (Hubbe et al. 2017) of NMC with fast viscosity recovery after pseudoplastic deformation, has also intensified its usage as a rheology modifier in coatings (Klemm et al., 2018; Hoeng et al. 2017); such behaviour has been explained by the interactions between the fibrils and fibril flocs (Koponen 2020) of NMC, that may also serve to enhance the cohesion between the integrated functional particles (EI Baradai et al., 2016).

There are still rare studies performed on using NMC as a functional entity in textile finishing. Cellulose nanocrystals (CNC) were applied by the pad-dry-cure method, to improve the absorbency and to enhance the colour strength of polyester fabric dyed with direct dyes (Chattopadhyay and Patel, 2016). CNC were also used to reinforce the polypyrrole/ $\mathrm{FeCl}_{3}$ coated cotton without affecting its conductivity (Hebeish et al., 2016), and to protect it from the influence of a high-energy electron beam (Hebeish et al., 2018). Bacterial nanocellulose (BC) was used to restore historic silk fabrics by reinforcement and improved protection against ultraviolet and ozone ageing (Wu et al. 2012). Cellulose fabrics were finished with allicin-conjugated nanocellulose to create durable antibacterial properties (Jafary et al. 2015).

In the present study, the microfibrillated cellulose (MFC) was used as a user-friendly and wear-related comfortable thin-layer and pattern-structure coating on FR-protective fabrics to improve their thermophysiological comfort (i.e. the moisture build-up, without affecting moisture transfer and breathability) after a hydrophobic finishing. Such an effect of MFC was expected, due to both its structured coating, as well as high moisture adsorption ability (Minelli et al., 2010) and an increase in oxygen permeability in the presence of moisture (Belbekhouche et al., 2011; Aulin et al., 2010). For that purpose, the MFC was screenprinted on the fabric surface. followed bv the printing of a hydrophobic polyacrylate (PA), using different pressure of the squeegee and different printing Loading [MathJax]/jax/output/CommonHTML/jax.js 
strategies (i.e. to print MFC on the same, or other side of the fabric as the PA). The influence of fabric thickness and structure (openness) on the coatings addon, penetration, moisture vapour transport and wetting properties were considered, as well as strength and abrasion resistance.

\section{Experimental}

\section{Materials}

Two woven flame-resistant (FR) fabrics with different constructions (Table 1) were used as provided by Tekstina Ltd (Slovenia). The fabrics were constructed as two-wefts woven fabrics (1/3 broken twill in the front weave, and 2/2 zigzag twill in the back weave) made from spun yarns (a mixture of modacryl $v s$. meta aramid and FR Lenzing viscose in a ratio of $40 / 37$ vs. 34/34, respectively) in both weft (which predominates on the back side of the fabric; i.e. the face that looks outward while wearing) and warp directions, and viscous filaments ( $22 \% \mathrm{vs}$. $32 \%$ ) which also appear in the weft direction, and predominate on the front side of the fabrics (i.e. the face that looks towards the wearer).

Commercially available microfibrillated cellulose (MFC) Exilva F-01-L consisting of approximately $22-50 \mu m$ long and up to $100 \mathrm{~nm}$ wide fibrils was provided by Borregaard AS, Norway. Analytical grade (Sigma Aldrich, Germany) hydroxyethyl cellulose (HEC, no. 308633) of 380.000 molecular weight (given viscosity of 300-400 mPas at $2 \mathrm{wt} \%$ ) was used as a water-retention additive.

Table 1

The constructional parameters of the used woven FR fabrics

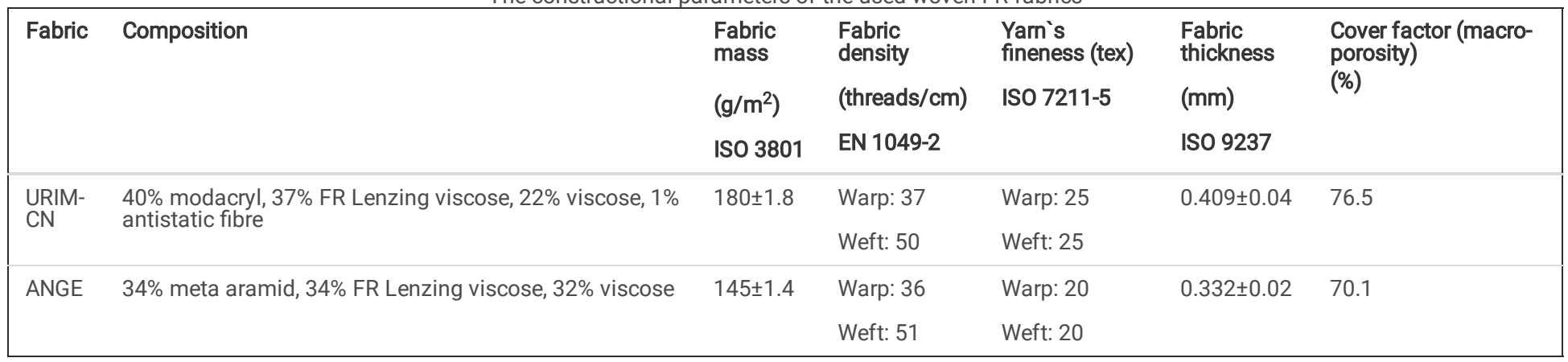

\section{Preparation of MFC dispersions and acrylate-based paste}

The $1 \mathrm{wt} \%$ and $1.5 \mathrm{wt} \%$ of MFC-based printing dispersions (viscosity of $17 \pm 2 \mathrm{dPa}$ s and $46 \pm 3 \mathrm{dPa}$, respectively,), were prepared by mixing the desired amount of water-dispersed MFC and pre-dissolved HEC, acting as a water retention additive. In the final printing dispersions, the concentration of HEC was $5 \mathrm{w} / \mathrm{w} \%$ from the dry weight of MFC.

The acrylate water-based synthetic printing paste (AP, pH of 8-8.5), consisting of $133.3 \mathrm{~g} / \mathrm{kg}$ polyacrylate self-crosslinking binder (Tubifast AS 30 ), $1.67 \mathrm{~g} / \mathrm{kg}$ ammonium water, $2.5 \mathrm{~g} / \mathrm{kg}$ polymeric silicone as an antifoam (CHT entschaumer BSN), $20 \mathrm{~g} / \mathrm{kg}$ melamine resin (Tubigat WAF 20), $18 \mathrm{~g} / \mathrm{kg}$ ammonium salt of polymeric carboxylic acids as a thickener (Tubivis DRL 600), acrylic-acid as a rheology additive (Tubigat R 130), all commercial products of CHT Bezema, Germany, adjusted to the viscosity of $105 \pm 5 \mathrm{dPa}$ s by the addition of destilled water, was prepared by Tekstina Ltd (Slovenia).

Both MFC-based dispersions and acrylate pastes were evaluated for rotation viscosity using a Haake rotational Viscotester V2 (Thermo Scientific, USA).

\section{Water-retention properties of MFC dispersions}

The water release was measured with an ÅA-GWR (Åbo Akademi Gravimetric Water Retention Device, GRADEK) (Sandås et al. 1989, Tappi Journal 72/12). Before the measurement, the samples were diluted with water to a total solids content of $0.2 \mathrm{wt} \%$. A known amount of the diluted sample ( $3 \mathrm{~g}$ ) was filtrated through the membrane filter (nominal pore size $5 \mu \mathrm{m}$ ) for $30 \mathrm{~s}$ with 0.5 bar pressure, and released water was collected and weighed. The results, the amount of released water from the amount of the sample $(\mathrm{g} / \mathrm{g})$, are given as an average of three measurements, and being recalculated in the percentage.

\section{Surface tension properties of MFC dispersions and acrylate-based paste}

The surface tension properties of both differently prepared MFC dispersions and acrylate-based paste were determined using a platinum Wilhelmy plate on a tensiometer (Krüss $\mathrm{GmbH}$, Germany). The tested liquid $(75 \mathrm{~mL})$ in the vessel was placed in a movable table under the Wilhelmy plate. The plate was suspended vertically $6 \mathrm{~mm}$ into the tested liquid, due to the relative high viscosity of the dispersions. The surface tension ( $\mathrm{Y}$ ) correlates to the force ( $\mathrm{F}$ ) measured when the plate is pulled out, and was calculated by the Wilhelmy equation $(\gamma=F /(l \cdot \cos \phi)$, where $/$ is the wetted perimeter $(2 \mathrm{w}+2 \mathrm{~d})$, $w$ is the plate width, $d$ is the plate thickness, and $\phi$ is the Contact Angle between the liquid and the platinum plate). The average values were calculated from at least four individual measurements.

\section{Zeta potential of MFC dispersion and textile fabrics`surfaces}

The zeta potential (ZP) of Milli-Q water dispersed 0.01 wt\% MFC suspension was carried out on a Zetasizer (Nano ZS ZEN360, Malvern Instruments Ltd., UK) at $25 \pm 0.1^{\circ} \mathrm{C}$, using the DTS1070 disposable folded capillary cell. The refractive index of 1.47 (cellulose), dispersion refractive index of 1.33 (milliQ), and viscosity of $0.8872 \mathrm{cP}$ were used. A field of $150 \mathrm{~V}$ was applied across the nominal electrode spacing of $16 \mathrm{~mm}$. The samples were measured over a pH range from 3 to 11 , being adjusted using $0.1 \mathrm{M} \mathrm{NaOH}$ and $0.1 \mathrm{M} \mathrm{HCl}$, respectively.

Loading [MathJax]/jax/output/CommonHTML/jax.js 
The Zeta Potential of the fabric surfaces was determined by measurement of the streaming current (SurPASS instrument, Anton Paar, Austria), using an Adjustable Gap Cell. In the cell, a single streaming channel is created between two samples with a flat surface, and the liquid streams along the sample surface (Grgac et al., 2017). A streaming current is generated when an electrolyte solution (1 $\mathrm{mM} \mathrm{KCl}$ ) is forced, by means of hydraulic pressure, to flow across a channel formed by two samples. The $\mathrm{pH}$ dependence of the Zeta Potential was determined in the range of $\mathrm{pH} 2.5-9$. The $\mathrm{pH}$ of the aqueous solution was adjusted with $0.1 \mathrm{~mol} / \mathrm{L} \mathrm{NaOH}$ to $\mathrm{pH}$, and was changed automatically by adding $0.1 \mathrm{~mol} / \mathrm{L} \mathrm{HCl}$.

\section{Screen-printing procedures}

The printing was performed on a Zimmer laboratory screen printing machine using a nickel-based rotary screen (SPG Prints B.V., Netherlands, former Stork) of 80 mesh size, $12 \%$ open area, $111 \mu \mathrm{m}$ of holes diameter, and $87 \mu \mathrm{m}$ of screen plate thickness, and steel-rod type squeegee of $15 \mathrm{~mm}$ in diameter, which was pushing the printing dispersion through the screen at a relevant pressure (magnet adjustable to no. 2 or 6 ) and rotating the screen at a relevant speed (manual setting, stage $5 \approx 6 \mathrm{~m} / \mathrm{min}$ ). The prints were performed as two-layer printings applied in two separate steps i) On the same, technical back side of the fabric (the side that looks outward while wearing), where the MFC-based dispersion was printed first, followed by printing of AP, or ii) On a different side of the fabric where the MFC was applied, on the technical front side (the side that looks towards the wearer), followed by AP on the back side, using the same printing sequence. After each printing step, the fabrics were dried at $100^{\circ} \mathrm{C}$ for $3 \mathrm{~min}$, using a laboratory heated air-circulation unit (Werner Mathis $\mathrm{AG}$, Switzerland), and finally cured at $170^{\circ} \mathrm{C}$ for 2 min to fix the AP coating using the same equipment unit.

\section{Fabrics' washing and drying}

The FR-fabrics were laundry washed (1x) according to the ISO 6330:2000 Standard in a domestic washing machine, Gorenje SensorCare model W8665K (MIX/Sintetic normal at $60^{\circ} \mathrm{C}$, centrifuge $1000 \mathrm{rpm}$ ) using detergent IEC BASE A (without bleaching agents; $66 \mathrm{~g} / 2 \mathrm{~kg}$ ), and dried at low temperature (one dot) in a domestic drying machine, Gorenje SensoCare model D82426.

\section{Fabric analysis}

All the fabrics were conditioned at standard conditions $\left(21 \pm 2^{\circ} \mathrm{C}\right.$ and $65 \pm 5 \%$ of relative humidity) prior to testing.

Fabric weight was measured and mass/area $\left(\mathrm{g} / \mathrm{m}^{2}\right)$ was calculated for each sample, and the add-on percentage was assessed by using the following equation: Add-on $(\%)=\left(m_{c}-m_{i}\right) / m_{i} \times 100$, where $m_{c}$ and $m_{i}$ are weights of the sample before and after the treatment, respectively; up to three measurements for each sample were assessed and the average value was reported.

The fabric's surface hydrophilicity and absorbency (ASTM D 5725-99) was assessed by measuring the fabric's Contact Angle / CA values using 3 mL drop of milliQ water (surface tension of $70 \mathrm{mN} / \mathrm{m}$ ) on the goniometer (Dataphysics, Germany, OCA 35 model), as well as the time of the milliQ drop staying on the fabric's surface (to soak into it). The wetting properties of selected samples were determined according to the capillary rise method, using the Tensiometer K12 (Krüss, GmbH Germany) and a special sample holder with $1 \mathrm{~g}$ of sample. A glass vessel, filled with $75 \mathrm{~mL}$ of milliQ water as the wetting liquid, was placed into the moving table, which rose until the tested liquid touched the lower edge of the sample holder. The software (Kruss, version 2.5.0.2305, LabDesk User Interface) monitored the increase in mass of the sample cylinder with respect to the capillary action and the time during the measurement. The obtained slopes of weight gained due to the milliQ water penetration as a function of time, presents the sample's absorbency rate, while the amount of test liquid uptake ( $\mathrm{g}$ milliQ/g) in equilibrium expressed their absorbent capacities. The measurements were performed at least five times for each selected sample, in order to obtain statistically significant results.

Scanning Electron Microscope (SEM) imaging of the selected fabric surfaces were performed to evaluate the print surface structuring and durability using a low-vacuum microscope (FEI Quanta 200 3D, Thermo Fisher Scientific Inc., USA).

Tensile (ISO 13934-1) and tear strength (ISO 13937-2) tests were carried out using a Tinius Olsen testing machine H10KT (Tinius Olsen Ltd., Redhill, United Kingdom) with a $1 \mathrm{kN}$ load cell. Five samples $(250 \pm 2 \mathrm{~mm} \times 50 \pm 1 \mathrm{~mm})$ from both the warp and the weft directions of preconditioned fabrics were taken randomly from the fabric for tensile testing, and then the maximum breaking force was detected for all samples, and, finally, the average value was calculated, expressed in $\mathrm{N}$. In the case of tear testing, five samples were first cut from the preconditioned fabric in both warp and weft directions, with the dimensions of $200 \pm 2 \mathrm{~mm} \times 50 \pm 1 \mathrm{~mm}$. Then a longitudinal slit of $100 \pm 1 \mathrm{~mm}$ was made in the length beginning from the centre of the width for all samples, and a mark of $25 \pm 1 \mathrm{~mm}$ from the uncut end of the strip, to indicate the position of the tear at the completion of the test. The average value of tear peaks was detected electronically, expressed in N. The strength/tear testing was performed at a gauge length of 200/100 mm, constant rate of extension of $100 \mathrm{~mm} / \mathrm{min}$, and preloading of $2 / 0 \mathrm{~N}$.

The air permeability (DIN 53887 / ISO 9237; Karl Schroeder KG, Materialprufmaschine D-6940, Germany) and water vapour resistance / WVR (ISO 11092:2014; KES-F7 Thermo Labo II, Kato Tech Co- Ltd., Japan) were analysed according to the relevant Standards; the results are given as the mean values of up to ten measurements for each sample.

Abrasion resistance of the front sides of fabrics was evaluated according to ISO 12947-2 using a Martindale M235 Abrasion and Pilling Tester (SDL Atlas Textile Testing Solution, China) with a specimen diameter of $38 \mathrm{~mm}$ and a pressure of $12 \mathrm{kPa}$. The weight before and after specified cycles of abrasion were measured, and the weight loss was calculated and reported as a percentage of the weight before the abrasion (ISO 12947-3). The weight loss and cycles were determined at the tearing of a min. of two threads and at the breakdown. At least 4 measurements for each selected sample were performed to obtain statistically significant results.

The flame-resistance of the front sides of fabrics was evaluated according to ISO 15025 by monitoring the ease of ignition of vertically oriented samples placed in a rectangular frame and exposed for 10 seconds in contact with a flame situated perpendicularly to the sample surface. If the samples ignited, the janition timo wac rocorded and then the moan value of the ignition time of five testings were determined.

Loading [MathJax]/jax/output/CommonHTML/jax.js 


\section{Results And Discussion}

\section{The effect of MFC printability on different fabric' surfaces}

The screen printing trials indicated that both $1 \mathrm{wt} \%$ and $1.5 \mathrm{wt} \%$ MFC dispersions (containing $5 \mathrm{w} / \mathrm{w} \%$ of HEC) transferred smoothly through the screens, provided uniform and repeatable printing of MFC without blocking the pores. This might be related to both high enough viscosity and yield stress of MFC dispersions, despite the relatively low solid contents (Nazari et al., 2016), as well as the addition of HEC, acting as a water retention additive and dispersant by keeping the fibrils disentangled (Kumar et al., 2016). However, the impact of FR fabric properties, such as surface chemistry and structure, may also have an important issue (Kumar et al., 2017) by influencing both MFC as well as acrylate-based paste (AP) adhesion and, thus, also layering and pattern stability after removal of the screen. The zeta potential (ZP) of the fabric surfaces, as well as surface-free tension (SFT) energies of printing dispersions have thus been evaluated in order to verify these characteristics.

As seen from Fig. 1, both fabric surfaces have overall negative zeta potential (ZP) at pH neutral conditions (Fig. 1a; at pH 6.9: ZP URIM-CN $\approx-19.73 \mathrm{mV}$, $\mathrm{ZP}_{\mathrm{ANGE}} \approx-25.6 \mathrm{mV}$ ), being supported with their good wetting properties. On the other hand, MFC dispersions possess high-enough surface-free tension (SFT) energies $(\approx 71 \pm 1.5 \mathrm{mN} / \mathrm{m})$ and good water-retention properties $(\approx 64.2 \%)$ (Fig. 1b). This shell influenced the predominant dispersive interactions (Van-derwaals forces and/or hydrogen bridges) between the viscose fibres and MFC, where some ionic repulsons could also be present due to the negatively charged MFC ( $\mathrm{ZP} \mathrm{P}_{\mathrm{MFC}} \approx-28.6 \mathrm{mV}$ ) that should have kept the cellulose microfibrils physically consistent, but also well adhered to the fabric surface. The significant differentiation of the water interfacial surface charges of the viscose fibres (contains acidic functional groups such as hydroxylic and carboxylic) against chemically-inert modacryl and aramide with smother surfaces, also enables them to form hydrophobic interactions. Such a viscose-modacryl/aramid blend is, thus, expected to ensure good adhesion, homogeneous layering and comparatively stable patterning of both MFC (interacting primarily with the highly hydrophilic viscose) and polyacrylate (AP with SFT $\approx 129.76 \pm 1.5 \mathrm{mN} / \mathrm{m}$, interacting primarily with the synthetic fibres) applied in the 2nd printing step and their chemical crosslinking during curing.

The patterning, layering and imprinting of MFC dispersions on fabric' surfaces, depending on the printing strategy (MFC printing on the back/B or face/F side of the fabric followed by AP applied on the back/B side), and their durability (attachment) after printing of a polyacrylate (AP), have been studied by SEM imaging. As presented in Fig. 2, the AP pastes were distributed equally as around $100 \mu \mathrm{m}$ large spherical patterns on both fabric surfaces (back sides of RefAP) and the yarns are seen clearly and appear smooth and regular; some spots can also be observed on the fabrics facess,$\in$ dicat $\in$ gpossib $\leq$ pe $\neq$ trationofAPthroughthem. Thepr $\int \in$ gofMFCasthefirstlayer(undertheAP) doesn'tchan $\geq$ thepaerns distribution and homogeneity, but shows clearly the presence of MFC, while giving a similar surface on the unprinted (face/F) side. This means that, in the printing process, some amount of PA paste may still be pushed through the fabric to the other side, and the MFC was co-crosslinked permanently within the subsequently printed polyacrylate coating. When MFC was printed on the front side of the fabrics, followed by the AP on the back side (MFC*-AP), the presence of MFC can also be visualised, while the yarns looks more glued together at certain areas, giving a more inhomogeneous surface. Much better penetration of AP through the thinner fabric with more open structure (ANGE) is also presumed to ensure better imprinting of MFC and co-crosslinking with AP within/through the fabric, independent of the MFC printing (on the same/back side as AP, or on the other/front side). On the other hand, in the case of thicker and less open URIM-CN physically larger MFCs look to block the PA penetrating, thus giving more surface deposited MFC, which is relatively well cocrosslinked within the AP and adhered to the fabric.

The air permeability and add-on percentage of differently treated fabrics have also been determined, to assess the effect of the MFC concentration and pressure of the squeegee on the printing's efficacy and durability (adhesion/attachment). A significant reduction (22.2\% and $19.5 \%$ ) of air permeability can be observed (Fig. 3) for both tested fabrics after printing of acrylate paste / AP (Ref-AP), which was additionally reduced (up to $28.5 \%$ and $48.6 \%$ ) when MFC was applied in the pre-printing step. This effect was more pronounced by using a highly (1.5 wt\%) MFC concentrated dispersion, lower pressure of the squeegee (no. 2) and structurally thinner and more open fabric structure (ANGE), followed by a higher pressure printing. Although the final content of MFC and AP on the fabrics after laundry washing could not be determined, due to the different amounts of AP applied and their effective crosslinking of AP and, thus, their varying removal during washing, we can still draw certain conclusions based on the total add-on values. The results indicate that although more superficial coated MFC (in the case of URIM-CN) might be better available for the co-crosslinking with the subsequent AP deposition, it migh affect the AP crosslinking more, and its adhesion with the fabric due to the hydrophilic nature of MFC acting on the interface, and thus resulting in around $2.2 \%$ reduced add-on values as compared to the references (Ref-AP). On the other hand, in the case of more into the fabric imprinted MFC (ANGE) it might even increase it up to around $1.2 \%$, regardless of which side of the fabric the MFC was applied. In addition, as there was almost no difference between the air permeability values where the MFC is pre-printed on the same side as the AP or on the other side of the fabrics, it can be concluded that the penetration of AP through the fabric can cocrosslink the MFC printed on the other side, however, add-on values of which depend again on the fabric structure. Furthermore, as the air-permeability in the case of ANGE was additionally reduced by applying higher (1.5 wt\%) MFC concentration, independent of the pressure of the squeegee, it may also be speculated that the MFC may got stuck and crosslinked more easily by AP in the internal structure of thinner and more open ANGE, while, in the case of thicker and less open URIM, it remained predominantly on the fabric outer surface, and blocked its further penetration through it, thus reducing the add-on.

\section{The effect of MFC printing on fabrics` water vapour resistance, surface wetting and moisture adsorption ability}

A high degree of water vapour permeability is supported by water vapour transfer from the skin through the fabrics into the environment. If the resistance to water vapour diffusion is high, the evaporation is low and the moisture movement is impeded, and the discomfort sensation of dampness and clamminess may arise. In addition, as the vapour moisture is transferred mainly through the inter-yarn spaces of the fabrics, the moisture diffusion and sorption-desorption ahilitv is alsn imnortant alono with fahric. thickness and construction.

Loading [MathJax]/jax/output/CommonHTML/jax.js 
From the air permeability test it has been observed that the fabrics

airpermeabilityisreducedbyapply $\in g A P$, and,$\in$ addition, byMFC, which $\in$ dicatestthefabrics porosity is generally reduced by the treatments. However, the differences in the WVR of the fabric do not follow the same pattern, which can be explained by different moisture vapour transmission mechanisms being associated with different diffusion (through the air spaces between the fibres and yarns and along the fibre itself) and the sorptiondesorption process. A thinner and more open ANGE, that contains water vapour (half-less) resistance meta-aramid fibres as compared to the modacrylic-based and less open URIM-CN (Varga et al., 2011), while the water vapour resistance (WVR) of Lenzing viscose FR is much higher due its high sorption capacity,

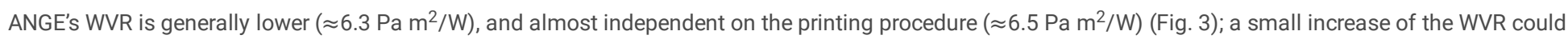
be observed for samples printed with $1.5 \mathrm{wt} \%$ MFC on the fabric front side - the side on which the WVR measurement was performed, which might be related to a higher adsorption ability of water vapour on this side. On the other hand, in the case of URIM-CN, the WVR was slightly reduced, from $\approx 6.94$ (Ref-AP) to $\approx 6.69 \mathrm{~Pa} \mathrm{~m} 2 / \mathrm{W}$ (pressure no. 2) and from $\approx 7.07$ (Ref-AP) to $\approx 6.98 \mathrm{~Pa} \mathrm{~m}^{2} / \mathrm{W}$ (pressure no. 6) by printing 1 wt\% MFC on the same side as AP, which might be due to a less dense or thinner and less homogenously distributed AP coating, associated with the co-crosslinking of MFC, as discussed above in the previous Section, being supported by lower add-on value. Such a conclusion may also be supported by the fact that WVR was increased again when being printed on the other, front side of the fabric.

Anyhow, by applying highly hydroscopic MFC (Minelli et al., 2010), the moisture regain of the fabric would be increased, causing higher diffusivity, and, by this, an increased moisture transfer through the sorption-desorption process. This would also enhance the flow of water vapour from the sweating skin to the environment (releases it in a dryer air), comparatively to a fabric which does not absorb, and reduces the moisture built up in the microclimate, whereas the fabric with less hygroscopicity will provide higher resistance to the water vapour transfer.

In order to confirm this prediction, the fabrics' surface wettability were evaluated on both sides of the fabric surfaces by measuring the Contact Angle / CA of a milliQ water drop in the moment of the contact and the time it stayed. Although the CA measurement is straightforward for solid material with a planar surface, and the analysis of fabrics is made complicated by the shape of fibres and relatively porous structure of fabrics, it can, however, be used to determine the conditions at the textile interface after coatings. As expected, and it can be seen from Fig. 4, both types of fabrics were fully hydrophilic; it was not possible to measure the CA values, as the water droplets penetrated immediately into the fabrics on both sides. However, the printing of polyacrylate (AP) on the backsides turned both fabrics into entirely (both-sides) hydrophobic $\left(C A \geq 100^{\circ}\right)$, among which ANGE can be classified as superhydrophobic, due to a CA $\geq 145^{\circ}$ (Zha et al., 2014), indicating that the AP can spread and diffuse more easily into this type of fabric and penetrate through it, thus covering both sides of the fabric surfaces entirely. It can also be observed that the time for a drop to stay on the surface is much shorter on fabric's front sides ( $<100 \mathrm{~s}$ ) compared to their back sides (>300 s), which indicated that the AP coating was thicker and more homogenously applied / crosslinked on the side of its application. However, when MFC was printed on the fabric under the AP, the fabric CA slightly reduced (from $\approx 130^{\circ}$ to $\approx 118^{\circ}$ ) and the drop penetrated into the fabric in a few seconds on both sides of the fabrics; this effect being more pronounced in the case of the less open URIM-CN and using higher pressure of the squeegee. On the other hand, when the MFC was applied on the other, front side of the fabric (MFC*), it kept it entirely hydrophilic (CA could not be measured) while preserving the back-side as hydrophobic $\left(\approx 124^{\circ}\right)$ and slower to wet $(150-270$ s); the effect being more pronounced in the case of using lower pressure (No. 2$)$ of the squeegee. This indicated again that MFC restricts the penetration of AP through less open URIM-CN fabric, being influenced by the thickness and pattern density of the printed MFC, which, in turn, had an effect on AP spreading, penetration, and, thus, polymerisation and co-crosslinking with the MFC, although, making the fabric side more hydroscopic. In the case of ANGE, this observation was insignificant due to the much more open structure and thinner fabric and phenomena of MFC and AP imprinting, as discussed above.

The water uptake kinetic and capacity measurements (Fig. 5) for differently printed URIM-CN, correlated well with these results, exhibiting a corresponding dependency on the fabrics' treatment. The absorbency curve of the sample printed with $1.5 \mathrm{wt} \%$ MFC under the AP showed the fastest absorbency rate (indicated by the steeper curve), meaning that this sample needed the shortest period for establishing the equilibrium (i.e. $44 \mathrm{~s}$ ) compared to the other samples (66-100 s), while the amount of absorbed milliQ in equilibrium was similar ( $\approx 200 \%)$ compared to the sample printed only with AP. This is an important finding, as the rapidity or rates in moisture absorbency can influence the fabric thermophysiological comfort greatly, while not increasing its overall hydrophilicity (water capacity adsorption), which may also have an adverse effect on the fabric's liquid moisture transmission behaviour, i.e. too high hydrophilic proportion will absorb the sweat from the skin more quickly, leaving it dry, but reduced liquid spreading, which may accumulate the moisture in the clothing causing a damp and sticky feeling. A small amount of MFC applied may thus act for quick absorption of the moisture from the skin, while the synthetic fibres and paternally-applied hydrophobic AP will help to spread the absorbed liquid to the outer surface of the fabric, due to their high wicking property.

\section{The effect of MFC printing on fabrics` tensile and tear strength}

The results of tensile and tear testing are presented in Fig. 6 . It is clear that the reference fabrics have lower tensile strength in the warp direction in comparison with the weft direction, due to the fabric construction. Namely, the fabrics have two weft systems and, thus, much higher weft density (around 50 threads $/ \mathrm{cm}$ ) in comparison with warp density (around 36.5 threads $/ \mathrm{cm}$ ).

The results also show that printing the URIM-CN with AP improves fabrics' tensile strength in both directions, by around $12-14 \%$ in the warp and up to $6.7 \%$ in the weft, while additional pre-printing of MFC gives an insignificant effect, independent of the side of its application; a small increase of tensile strength can be observed only in the case of the MFC-AP sample and by using higher (No. 6) squeegee pressure, which may be related to a small imprinting of coatings into the fabric structure. In the case of ANGE fabric, the tensile strength was slightly improved (up to $6.8 \%$ ) only in the weft direction when using lower (1 wt\%) MFC concentration, independent of its application (on the back or front*side), which is in good agreement with previous discussions (add-on values). While the ANGE fabric is made of yarns of 20 tex and has around the same warp/weft densities as URIM-CN fabric (with yarn fineness of 25 tex), it has a lower cover factor (70.1\%), e.g. less fabric area is fulfilled with the yarns and, consequently, less yarn surface area is available for printing per fabric unit area. The fabric is woven in a two-weft weave, and both sides of the fabric have predominant weft threads with applied MFC and AP layers, which can withstand higher tensile Loading [MathJax]/jax/output/CommonHTML/jax.js :h are rarely visible at both sides of the fabric (being supported by SEM images).

Page 6/13 
Due to their two-wefts construction, fabrics show lower tear strength of warp threads in comparison with weft threads; i.e. the lower density of warp threads offers lower resistance against tear propagation. However, in the case of URIM-CN with higher cover factor, a slightly improved (11\%) of warp tear strength can be noticed when AP is applied to the fabric by surface printing (squeegee pressure No. 2). On the other hand, a slight increase (8.8\%) of weft tear strength was detected only when MFC was pre-printed under the AP, while the warp tear strength was reduced, as compared to the reference fabric (untreated fabric). In the case of using higher squeegee pressure (No. 6), all the printing procedures changed the original structure (i.e. spread out the yarns) of the fabric slightly, and thus reduced the weft tear strengths. Conversely, in the case of more open and thinner ANGE fabric, an obvious (24-16.4\%) reduction of weft tear strength could be noticed after applying AP, being more significant by using lower pressure of the squeegee, and being additionally reduced (up to $24.8 \%$ ) by also applying MCF under the AP; the warp tear strength remained almost the same as in the case of untreated samples. Such a fabric structure allows the weft threads (which predominate on the front/back sides) to move apart from each other because of the imprinted MFC (as seen from SEM images), thus giving lower resistance to tear propagation.

It is obvious that the type of woven structure plays an important role in the efficacy of printing, where the weft-directed threads (made of the blends of hydrophobic meta-aramide/acrylic fibres and FR viscose) are more exposed to the printing rather than warp threads (also containing hydrophilic viscose fibres on the front side). Such a structure, as well as the cover factor, both dictate not only the adhesion of the fibres but also the MFC and AP add-on and their imprinting, and, consequently, the fabric's tensile and tear strength. The MFC can, thus, be imprinted better into the ANGE fabric, which slightly improved tensile strength in both directions and warp tear strength, while the weft tear strength was reduced as compared to the original fabric.

\section{The effect of MFC printing on fabric's abrasion resistance}

Textile finishing or surface modification can change the wear or abrasion resistance properties of a fabric significantly, being an important parameter for protective clothing, as it might lead to the complete destruction of the textile during wearing. The abrasion resistance properties of differently treated fabrics have been studied on the front side of fabrics, which would be in contact with the skin during wearing. The weight loss and cycles were determined at the tearing of a min of two threads and at the breakdown. As seen from the results presented in Fig. 7, already the printing of AP on the back-side improved the abrasion resistance of both fabrics compared to the non-treated ones, by a gradual increase of their weight loss percentage, resulting in a resistance up to around 32000-34000 and 41000 cycles. By applying the $1.5 \mathrm{wt} \%$ MFC under the AP, the breakage of ANGE was additionally improved to 45000 cycles, while applying MFC on the front/tested side improved it further, since the breakage occurred at 50000 cycles (ANGE) and at 45000 cycles for URIM-CN. This means that MFC also contributed to the resistance of abrasion by covering the fibres (predominantly viscose) and, beside the AP, further gluing them together (SEM, Fig. 2) to withstand higher and long-term applied stress better. Due to the higher resistance of abrasion, the mass loss of MFC treated samples was also kinetically slower by approximately $5 \%$ than the other samples. Higher mass loss means that connections between fibres are weaker, which is comparative with the general trend for untreated samples (Ref), resulting in a rougher surface, due to which higher contact points at the surface increase the frictional force, leading to a decrease in the abrasion resistance of textiles.

\section{The effect of MFC printing on fabric's flame-resistance}

The front sides of differently coated fabrics were exposed to the flame according to ISO 15025 (Fig. 8) in both warp and weft directions, however, showing no difference as compared to the reference, ie. no ignition after contact with the flame for $10 \mathrm{sec}$, thus still providing high protection.

\section{Conclusion}

The microfibrillated cellulose (MFC) was screen-printed on FR-protective fabrics, followed by the printing of a hydrophobic polyacrylate using different pressures of the squeegee and different printing strategies (i.e. to print MFC on the same or other side of the fabric as the polyacrylate), thus to improve their thermophysiological comfort without affecting breathability and mechanical properties. The coatings

add-on, pe $\neq$ tration, airpermeability, moisturevapourtransp or $t$ and we $\in g \propto$ ertieswereconsred, aswellasstren $>h$ and abrasionresisti

properties were affected primarily by the coatings' add-on and their imprinting into the fabric (thus influenced by the fabric openness and thickness, and the pressure of the squeegee), and secondly on the way of MFC pre-printing, that may have preserved one side of the fabric as hydrophilic, while improving its surfaces wetting, moisture uptake kinetic and capacity, and water vapour transfer. Improved tensile and warp tear strengths are confirmed, as well as abrasion resistance. The coatings had no influence on the flammability of the textiles. This is the first study showing potential usage of nanocellulose as a green and user friendly nanomaterial also in textile coating.

\section{Declarations}

\section{Conflicts of interest}

The authors declare that they have no conflicts of interest to reveal.

\section{Funding}

This project has received funding from the European Union's Horizon 2020 Research and Innovation Programme (Grant Agreement No. 760601), as well as from the Slovenia Research Agency (Grant Agreement No. L2-9249 and Research Programme P2-0118).

\section{References}

Abitbol T, Rivkin A, Cao Y, Nevo Y, Abraham E, Ben-Shalom T, Lapidot S, Shoseyov O (2016) Nanocellulose, a tiny fiber with huge applications. Curr Opin Bintech 39·76-88 httns//dni ora/10 1016/i copbio.2016.01.002

Loading [MathJax]/jax/output/CommonHTML/jax.js 
Aulin C, Gällstedt M, Lindström T (2010) Oxygen and oil barrier properties of microfibrillated cellulose films and coatings. Cellulose 17:559-574. doi:10.1007/s10570-009-9393-y

Belbekhouche S, Bras J, Siqueira G, Chappey C, Lebrun L, Khelifi B, Marais S, Dufresne A (2011) Water sorption behavior and gas barrier properties of cellulose whiskers and microfibrils films. Carbohydr Polym 83:1740-1748. doi:10.1016/j.carbpol.2010.10.036

Boufi S, González I, Delgado-Aguilar M, Tarrès Q, Pèlach MÀ, Mutjé P (2016) Nanofibrillated cellulose as an additive in papermaking process: A review. Carbohydr Polym 154:151-166. https://doi.org/10.1016/j.carbpol.2016.07.117

Chattopadhyay DP, Patel BH (2016) Synthesis, characterization and application of nanocellulose for enhanced performance of textiles. J Textile Sci Eng 6:248-255. doi:10.4172/2165-8064.1000248

Du X, Zhang Z, Liu W, Deng Y (2017) Nanocellulose-based conductive materials and their emerging applications in energy devices-A review. Nano Energy 35:299-320. https://doi.org/10.1016/j.nanoen.2017.04.001

El Baradai O, Beneventi D, Alloin F, Bongiovanni R, Bruas-Reverdy N, Bultel Y, Chaussy D (2016) Microfibrillated cellulose based ink for eco-sustainable screen printed flexible electrodes in lithium ion batteries. J Mater Sci Technol 32:566-572. https://doi.org/10.1016/j.jmst.2016.02.010

Grgac SF, Bischof S, Pušić T, Petrinić I, Luxbacher T (2017) Analytical assessment of the thermal decomposition of cotton-modacryl knitted fabrics. Fibres Text East Eur 25/6(126):59-67. DOI: 10.5604/01.3001.0010.5372.

Havenetih G. In: Elsner P, Hatch K, Wiggert-Alberti W, editors. Textiles and the Skin, Curr. Probl. Dermatol, Clothing and Thermolegulation, Basel: Karger, 2003. 35-49, DOI:10.1159/isbn.978- 3-318-00863-0.

Hebeish A, Farag S, Sharaf S, Shaheen TI (2016) Advancement in conductive cotton fabrics through in situ polymerization of polypyrrole-nanocellulose composites. Carbohyd Polym 151:96-102 https://doi.org/10.1016/j.carbpol.2016.05.054

Hebeish A, Farag S, Shaheen TI (2018) High performance fabrics via innovative reinforcement route suing cellulose nanoparticles. J Text I 109:186-194. https://doi.org/10.1080/00405000.2017.1335377

Hoeng F, Denneulin A, Reverdy-Bruas N, Krosnicki G, Bras J (2017) Rheology of cellulose nanofibrils/silver nanowires suspension for the production of transparent and conductive electrodes by screen printing. Appl Surf Sci 394:160-168. http://dx.doi.org/10.1016/j.apsusc.2016.10.073

Hubbe MA, Tayeb P, Joyce M, Tyagi P, Kehoe M, Dimic-Misic K, Pal L (2017). Nanocellulose rheology - rich aqueous suspensions: A review, BioResources 12(4):9556-9661. https://doi.org/10.15376/biores.12.4. Hubbe

Jafary R, Khajeh Mehrizi M, Hekmatimoghaddam SH, Jebali A (2015) Antibacterial property of cellulose fabric finished by allicin-conjugated nanocellulose. J Text Inst 106:683-689. doi: 10.1080/00405000.2014.954780

Jonoobi M, Oladi R, Davoudpour Y, Oksman K, Dufresne A, Hamzeh Y, Davoodi R (2015) Different preparation methods and properties of nanostructured cellulose from various natural resources and residues: a review. Cellulose 22:935-969. https://doi.org/10.1007/s10570-015-0551-0

Kaushik M, Moores A (2016) Review: nanocelluloses as versatile supports for metal nanoparticles and their applications in catalysis. Green Chem 18(3):622637. https://doi.org/10.1039/C5GC02500A

Klemm D, Cranston ED, Fischer D, Gama M, Kedzior SA, Kralisch D, Kramer F, Kondo T, Lindström T, Nietzsche S, Petzold-Welcke K, Rauchfuß F (2018) Nanocellulose as a natural source for groundbreaking applications in materials science: Today's state. Materials Today 21(7):720-748.

https://doi.org/10.1016/j.mattod.2018.02.001

Koponen Al (2020) The effect of consistency on the shear rheology of aqueous suspensions of cellulose micro- and nanofibrils: a review. Cellulose 27:18791897. https://doi.org/10.1007/s10570-019-02908-w

Krifa M, Prichard C (2020) Nanotechnology in textile and apparel research - an overview of technologies and processes. J Text Inst 111(12):1778-1793. https://doi.org/10.1080/00405000.2020.1721696

Kumar V, Elfving A, Koivula H, Bousfield D, Toivakka M (2016) Roll-to-roll processed cellulose nanofiber coatings. Ind Eng Chem Res 55:3603-3613.

Kumar V, Koppolu VR, Bousfield D, Toivakka M (2017) Substrate role in coating of microfibrillated cellulose suspensions. Cellulose 24:1247-1260. DOI:10.1007/s10570-017-1201-5

Minelli M, Baschetti MG, Doghieri F, Ankerfors M, Lindström T, Siró I, Plackett D (2010) Investigation of mass transport properties of microfibrillated cellulose (MFC) films. J Membr Sci 358:67-75. doi:10.1016/j.memsci.2010.04.030

Nazari B, Kumar V, Bousfield DW, Toivakka M (2016) Rheology of cellulose nanofibers suspensions: boundary driven flow. J Rheol 60:1151-1159. D0I: $10.1122 / 1.4960336$

Stoppa M, Chiolerio A (2014) Wearable electronics and smart textiles: a critical review. Sensor 14:11957-11992. https://doi.org/10.3390/s140711957 Loading [MathJax]/jax/output/CommonHTML/jax.js

Page $8 / 13$ 
Varga K, Noisternig MF, Griesse UJ, Aljaž L, Koch T (2011) Thermal and sorption study of flame-resistant fibers, Lenzinger Berichte 89:50-59.

Zeng W, Li Q, Chen S, Wanf F, Tao XM (2014) Fiber-based wearable electronics: a review of materials, fabrication, devices and applications. Adv Mater 26:5310-5336. https://doi.org/10.1002/adma.201400633

Zeng Z, Wu T, Han D, Ren Q, Siqueira G, Nyström G (2020) Ultralight, flexible, and biomimetic nanocellulose/silver nanowire aerogels for electromagnetic interference shielding. ACS Nano 14(3):2927-2938. https://doi.org/10.1021/acsnano.9b07452

Zha H (2014) Definitions for hydrophilicity, hydrophobicity, and superhydrophobicity: getting the basics right. J Phys Chem Lett 5:686-688. Doi: dx.doi.org/10.1021/jz402762h

Zhu L, Naebe M, Blanchonette I, Wang X (2018) Mechanical properties of bifacial fabrics. Tex Res J. 88(12):1335-1344. doi:10.1177/0040517517700193

Zhu L, Naebe M, Blanchonette I (2017a) Moisture transfer properties of bifacial fabrics. Text Res J 87:1096-1106.

Zhu L, Naebe M, Blanchonette I (2017b) Heat transfer properties of bifacial fabrics. Text Res J 87:2307-2313.

Wang Z, Lee YH, Kim SW, Seo JY, Lee SY, Nyholm L (2020) Why cellulose-based electrochemical energy storage devices? Adv Mater https://doi.org/10.1002/adma.202000892

Wu SQ, Li MY, Fang BS, Tong H (2012) Reinforcement of vulnerable historic silk fabrics with bacterial cellulose film and its light aging behavior. Carbohyd Polym 88(2):496- 501. https://doi.org/10.1016/j.carbpol.2011.12.033

\section{Figures}
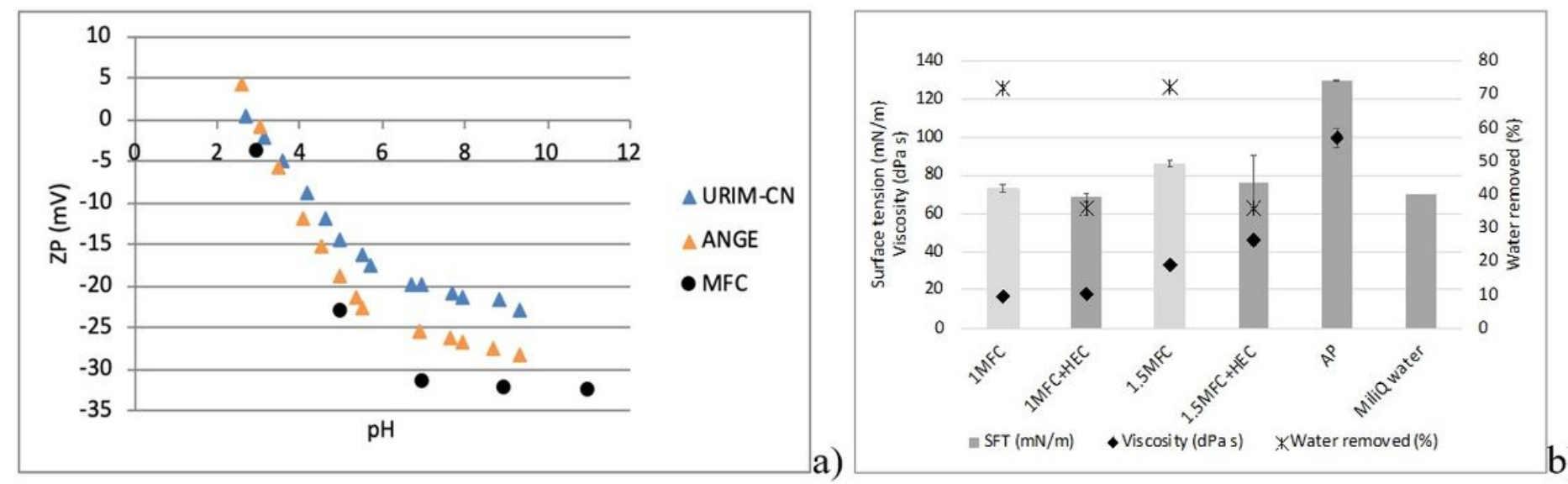

Figure 1

a) Zeta potential (ZP) values of FR-fabric surfaces (back-sides), and b) Surface tension, rotational viscosity and water retention capacity of 1-1.5 wt\% MFC based dispersions (with/without addition of $5 \mathrm{w} / \mathrm{w} \% \mathrm{HEC}$ ) and acrylate-based paste (AP) used for printing. 

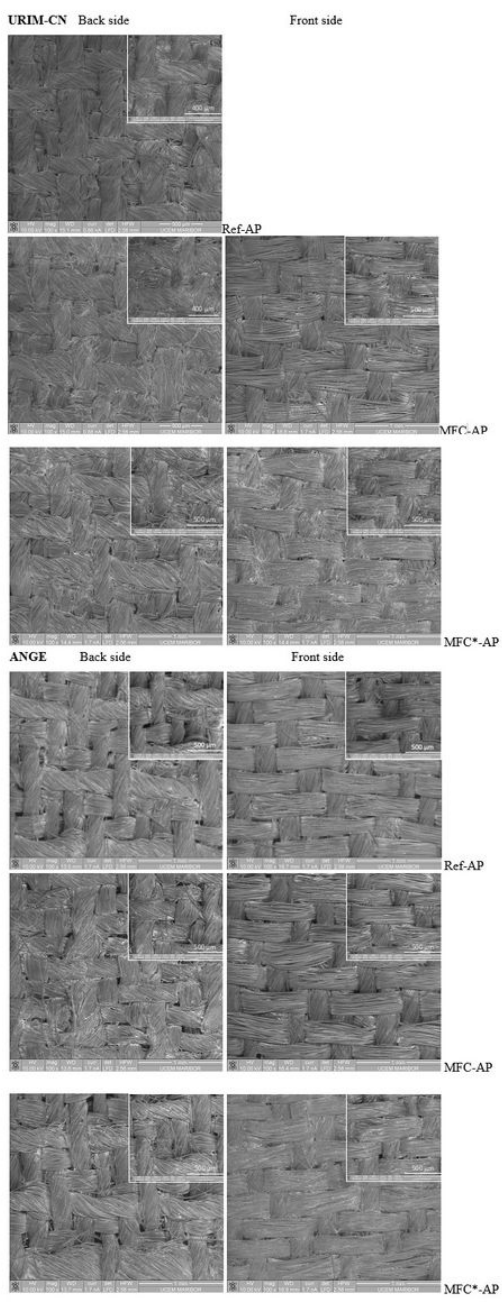

\section{Figure 2}

SEM images of differently printed fabrics using (1 wt\%) MFC dispersions and higher (no. 6) pressure of the squeegee, performed at 100x and 200x (inserted images) magnifications. Ref-AP: Fabric printed with AP on the back side. MFC-AP: Fabric printed with MFC followed by AP, both on the back side. MFC*-AP: Fabric printed with MFC on the front side followed by AP printed on the back side. 

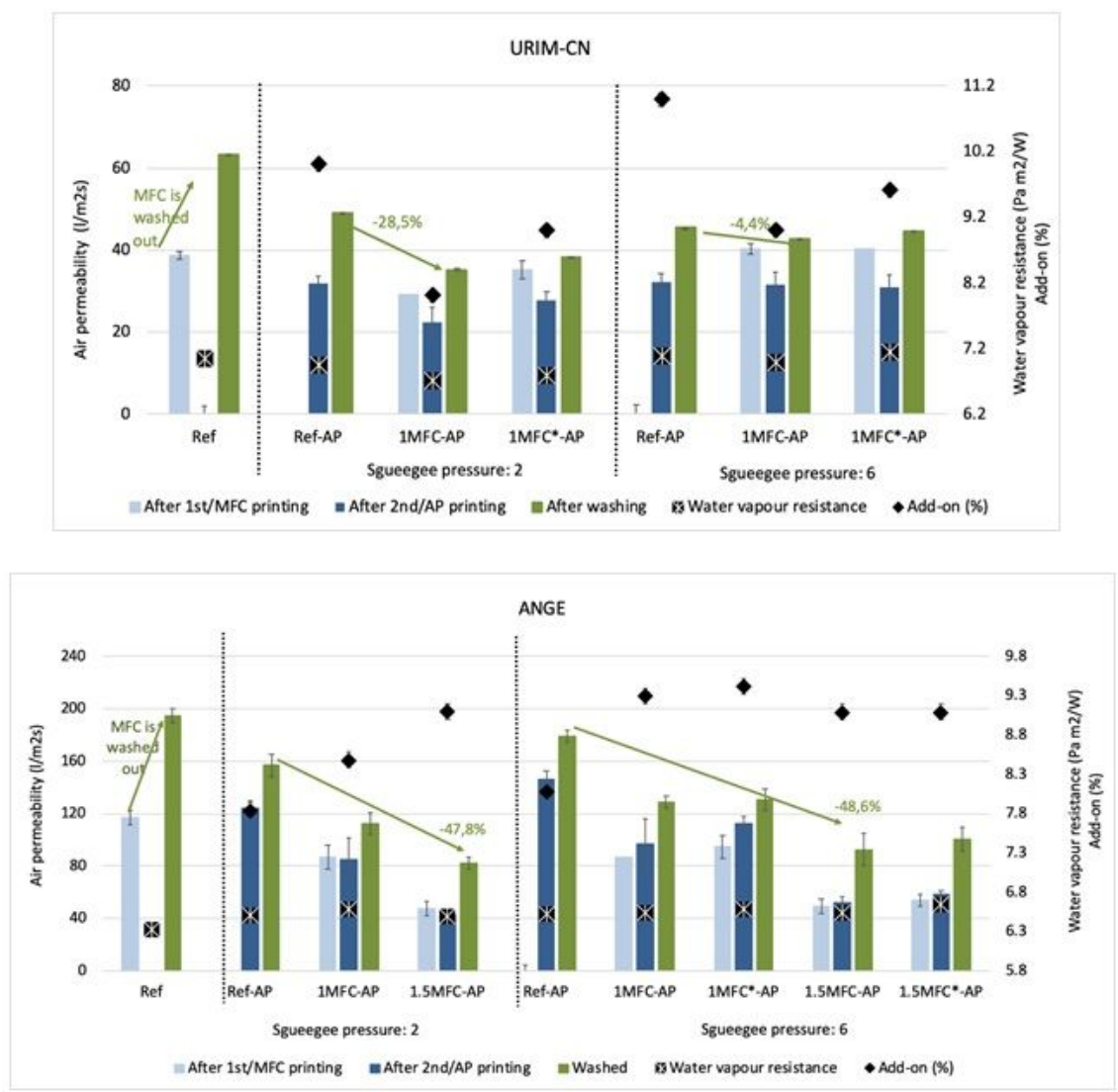

\section{Figure 3}

The effect of MFC printing (back or front* side) and squeegee pressure (nos. 2 and 6), followed by acrylate paste (AP) post-printing (back side), on fabrics add-on values, air permeability and water vapour resistance.

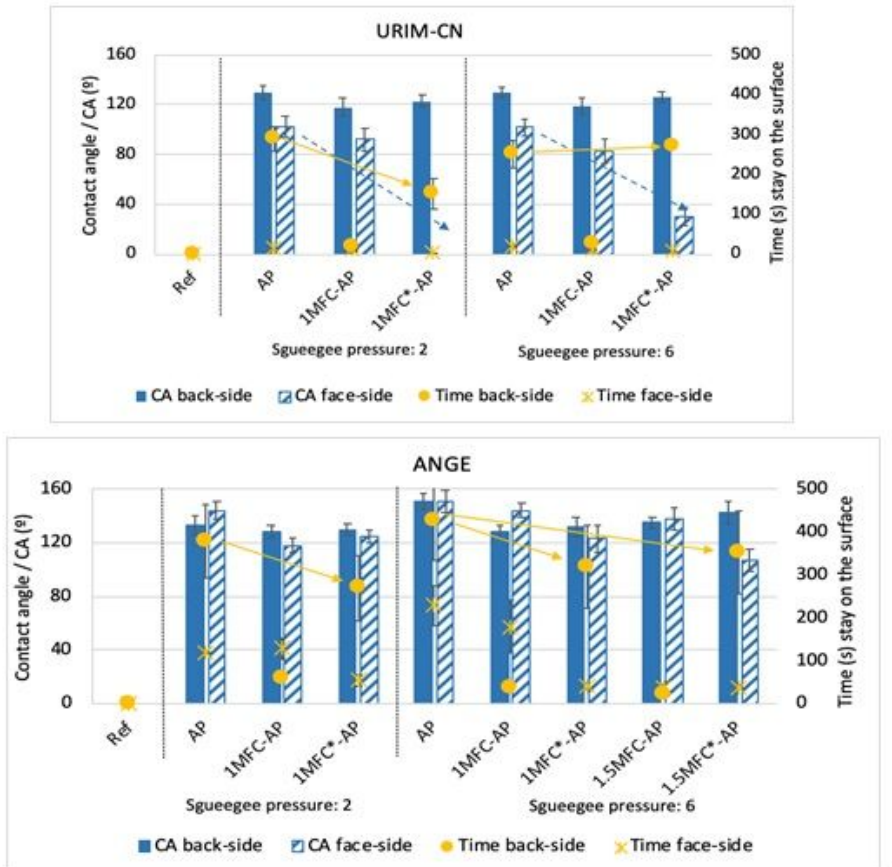

Figure 4 
The effect of MFC printing (back or front side*) using different squeegee pressures (nos. 2 and 6), followed by acrylate paste (AP) post-printing (back side), on Contact Angle (CA) values and time of milliQ water drop staying on the surface, measured on both-sides of the fabrics.
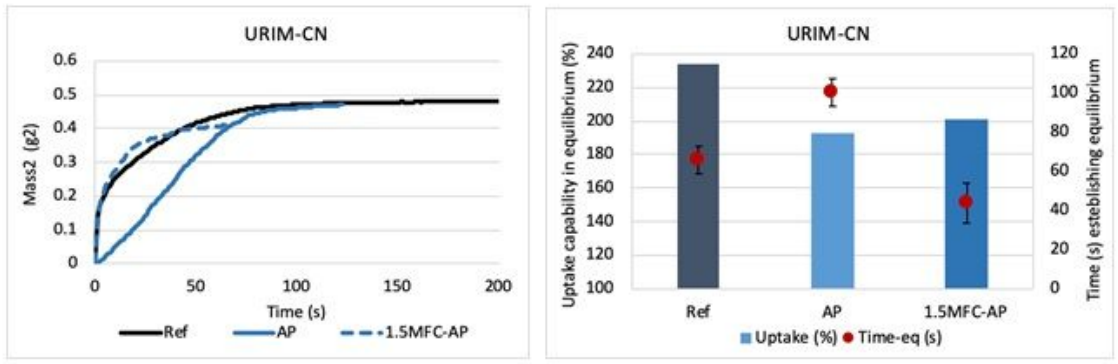

\section{Figure 5}

The effect of MFC printing, followed by acrylate paste (AP) post-printing (both on the back side), on milliQ water uptake and time to established equilibrium. The higher (no. 6) pressure of the squeegee was used.

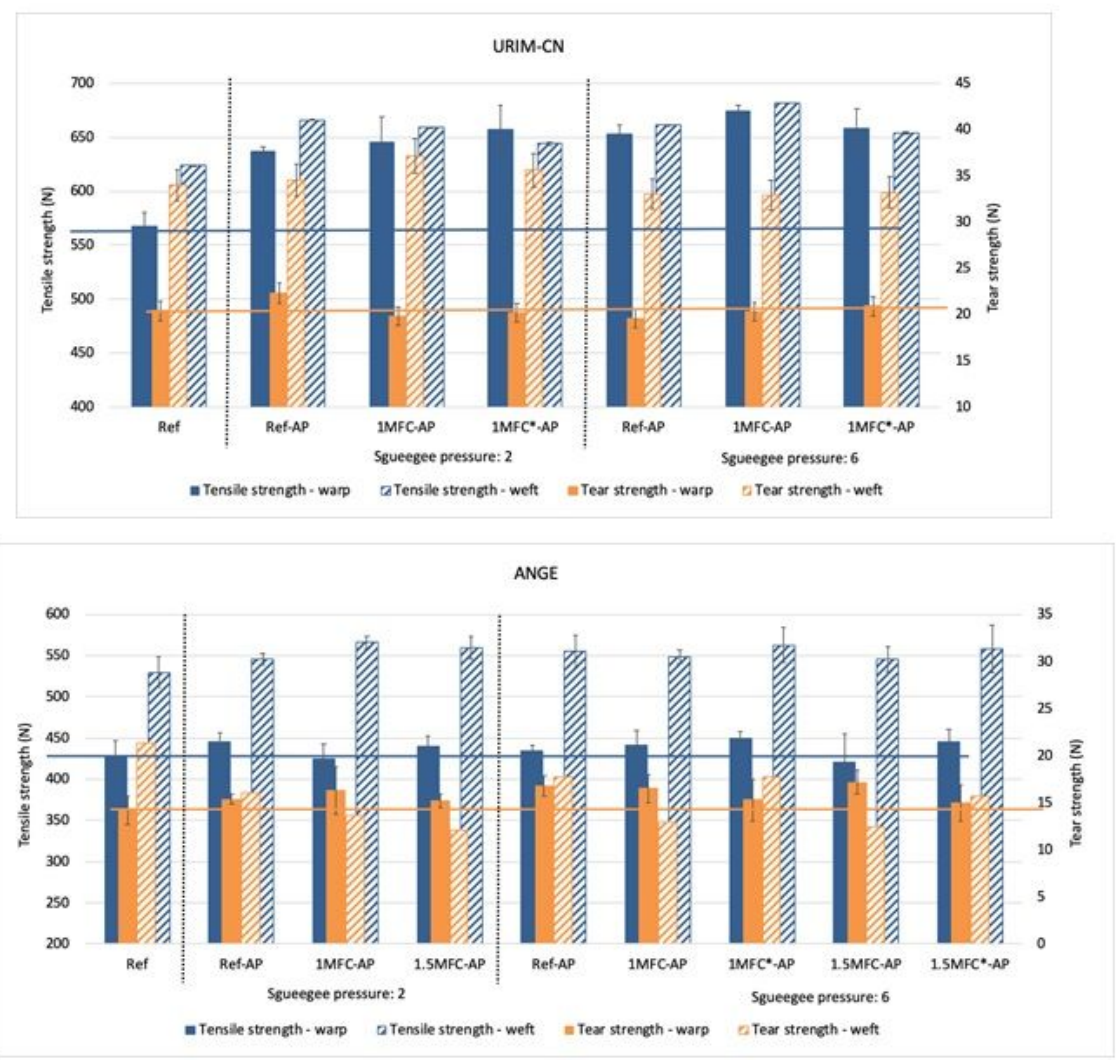

\section{Figure 6}

The effect of MFC printing (back or front* side) and squeegee pressure (nos. 2 and 6), followed by acrylate paste (AP) post-printing (back side), on the tensile and tear strength properties of fabrics. 


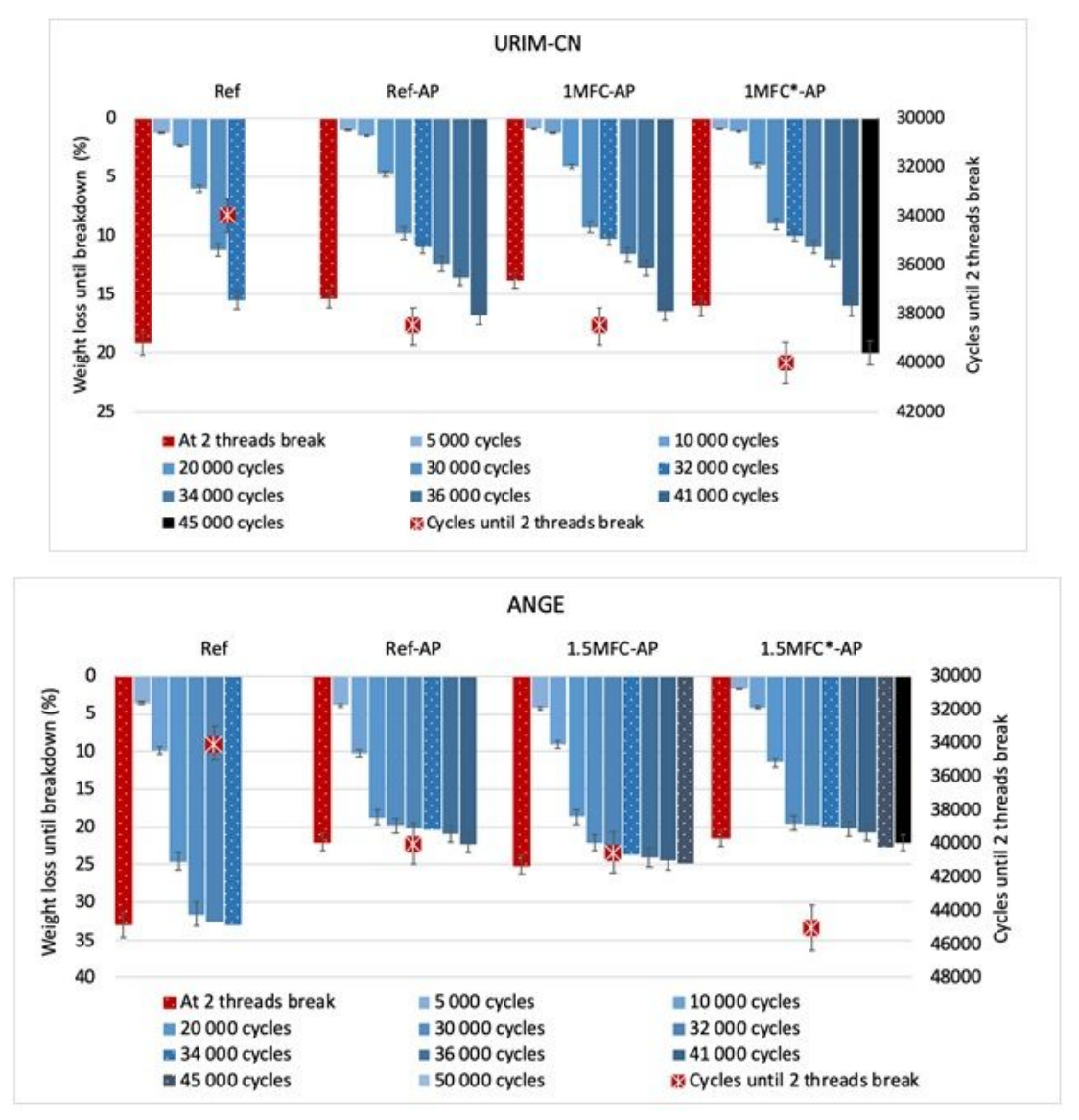

\section{Figure 7}

The effect of MFC printing (back or front side*), followed by acrylate paste (AP) post-printing (back side), on the abrasion resistance properties of the front sides of the fabrics.
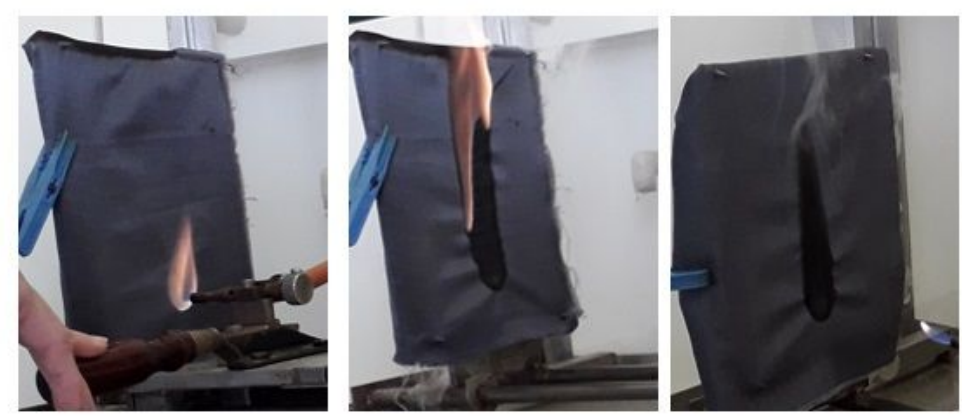

Figure 8

Flammability testing of 1.5MFC-AP printed fabric in compliance with EN ISO 15025. 